\title{
PENDIDIKAN KECAKAPAN HIDUP MELALUI PELATIHAN PAKAN IKAN MENGGUNAKAN MESIN PENGOLAH PAKAN IKAN DI DESA CIPEUNDEUY KECAMATAN CIPEUNDEUY KABUPATEN BANDUNG
}

\author{
Ahmad Munandar ${ }^{1}$, Nurwathi ${ }^{2}$, Udin Komarudin ${ }^{3}$, Dadang Supriatna ${ }^{4}$, Agus Sunarya ${ }^{5}$ \\ 1,2 Teknik Industri Universitas Sangga Buana, ${ }^{3}$ Teknik Mesin Universitas Widyatama, \\ 4,5 Badan Teknologi Atom Nasional \\ ${ }^{1}$ korespondensi: ahmad.munandar@usbypkp.ac.id
}

\begin{abstract}
ABSTRAK
Kemampuan masyarakat Indonesia dalam mengatasi permasalahan kehidupan terutama yang menyangkut kehidupan sehari-hari, sebagian besar masih mengandalkan potensi alam sekitar. Sayangnya potensi alam tersebut tidak diolah menjadi suatu produk yang memiliki nilai tambah. Terutama saat potensi alam perlu mendapat sokongan dari luar wilayah tersebut. Kecamatan Cipeundeuy kabupaten Bandung, terdapat sentra petani ikan, tepatnya di Desa Cipeundeuy, Mereka sangat bergantung dari penghasilan sektor ini, dan dalam aktifitasnya memerlukan bahan baku pakan ternak ikan cukup banyak setiap harinya. Permasalahan muncul setelah bahan baku cukup mahal, karena pakan ternak ikan didatangkan dari daerah lain seperti Jakarta dan Bandung.

Salah satu solusi yang diberikan adalah dengan memberikan pelatihan keterampilan cara membuat pakan ikan dengan menggunakan limbah makanan yang ada disekitar petani ikan seperti dedak (limbah padi), ampas tahu, dan sisa tulang ikan, dan lain-lain menggunakan Mesin Pengolah Pakan Ikan. Melalui pengolahan pakan ikan mandiri, petani dapat mengurangi biaya produksi budidaya ikan tersebut.
\end{abstract}

Kata Kunci: Kecakapan Hidup, Pakan Ikan.

\begin{abstract}
The ability of the Indonesian people to overcome life problems, especially those concerning daily life, mostly still rely on the potential of the surrounding nature. Unfortunately, this natural potential is not processed into a product that has added value. Especially when the natural potential needs support from outside the region. Cipeundeuy Subdistrict, Bandung Regency, there is a fish farmer center, precisely in Cipeundeuy Village, They are very dependent on the income of this sector, and in their activities require quite a lot of fish feed raw materials every day. Problems arise after the raw materials are quite expensive, because fish feed is imported from other areas such as Jakarta and Bandung.One of the solutions provided is to provide skills training on how to make fish feed using food waste that is around fish farmers such as bran (rice waste), tofu dregs, and fish bone residue, and others using Fish Feed Processing Machines. Through independent fish feed processing, farmers can reduce the production costs of the fish farming.
\end{abstract}

Keywords: Life Skills, Fish Feed

\section{PENDAHULUAN}

Kemampuan masyarakat Indonesia dalam mengatasi permasalahan kehidupan terutama yang menyangkut kehidupan sehari-hari, sebagian besar masih mengandalkan potensi alam sekitar. Sayangnya potensi alam tersebut tidak diolah menjadi suatu produk yang memiliki nilai tambah. Terutama saat potensi alam perlu mendapat sokongan dari luar wilayah tersebut.

Berdasarkan survey yang kami lakukan di desa Cipeundeuy, kecamatan Cipeundeuy 
kabupaten Bandung, terdapat sentra petani ikan, tepatnya di Desa Cipeundeuy, Mereka sangat bergantung dari penghasilan sektor ini, dan dalam aktifitasnya memerlukan bahan baku pakan ternak ikan cukup banyak setiap harinya.

Permasalahan muncul setelah bahan baku cukup mahal, karena pakan ternak ikan didatangkan dari daerah lain seperti Jakarta dan Bandung. Masalah terkait pakan ikan merupakan persoalan klasik yang dihadapi pembudi daya iklan. Pakan ikan menjadi beban yang signifikan karena diperkirakan dapat mencakup sekitar 60 hingga 70 persen dari keseluruhan biaya produksi [1]. Kualitas pakan yang dikonsumsi sangat berpengaruh bagi pertumbuhan ikan [2]. Pertumbuhan ikan bergantung kepada beberapa faktor yaitu jenis ikan, sifat genetis, dan kemampuan memanfaatkan makanan, ketahanan terhadap penyakit serta didukung oleh faktor lingkungan seperti kualitas air, pakan dan ruang gerak atau padat penebaran [3].

Di sisi lain, masih tingginya angka pengganguran di daerah tersebut, disamping karena rendahnya pendidikan, untuk membuat lahan perikanan terapung memerlukan biaya yang tinggi.

Melihat adanya peluang yang saling keterkaitan antara kebutuhan pakan ternak ikan, pengangguran, keterampilan dan peningkatan pedapatan masyarakat, maka kami berusaha memberikan stimulus berupa Pelatihan membuat pakan ternak ikan. Dalam pelatihan ini masyarakat akan diberi keterampilan cara membuat pakan ternak ikan dengan menggunakan limbah makanan seperti Dedak (limbah padi), Ampas tahu, dan sisa tulang ikan, dan lain-lain, serta akan dibentuk kelompok-kelompok usaha pengolah pakan ternak ikan. Sehingga dengan dilaksanakan pelatihan, peternak ikan tidak perlu lagi membeli pakan ternak ikan dari luar, cukup membeli dari kelompok yang membuat pakan ternak ikan yang ada di daerahnya. Pelatihan diharapkan akan mampu mengatasi pengganguran dan dapat meningkatkan pendapatan masyarakat sekaligus memenuhi kebutuhan pakan ternak ikan secara mandiri di daerah tersebut.

\section{METODE}

Metode kegiatan pengabdian masyarakat ini secara umum terdiri dari :

\section{Tahapan Observasi}

Tahap ini yang dilakukan adalah observasi berdasarkan kondisi yang terjadi di masyarakat serta peluang untuk pemecahannya. Observasi dilakukan langsung di Desa Cipeundeuy Kecamatan Cipeundeuy Kabupaten Bandung. Observasi difokuskan kepada potensi yang ada di desa Cipendeuy, dimana terdapat banyak peternak ikan Jaring Terapung. Peternak ikan jaring terapung ini, memerlukan Pakan Ternak ikan sangat besar. Dari hasil observasi di lapangan menunjukan bahwa sebagian besar pemilik jaring terapung adalah orang luar desa Cipeundeuy, sedangkan warga setempat sebagian besar hanyalah sebagai buruh dari jaring terapung tersebut, disisi lain masih banyaknya pengangguran didaerah tersebut 
Dari hasil observasi, ditemukan beberapa permasalahan seperti; 1. Angka Pengangguran cukup tinggi, 2. Pekerjaan sambilan sebagai buruh ikan, 3. Pendidikan rendah (hanya tamatan SD), dan 4. Warga sekitar waduk sebagian besar hanya sebagai penonton (pengganggur) atau sebagai kuli kasar (tidak tetap) dari pemilik jaring terapung.

\section{Tahapan Perancangan dan Pembuatan}

\section{Perancangan}

Beberapa penelitian terdahulu yang berkaitan dengan perancangan mesin pakan ikan yaitu Silvia Uslianti, Junaidi, dan Muhammad Saleh, (2014) Rancang Bangun Mesin Pelet Ikan Untuk Kelompok Usaha Tambak Ikan, dari Pogram studi Teknik Elektro Fakultas Teknik Universitas Tanjungpura. Pelet ikan yang dapat dihasilkan dengan menggunakan mesin pelet ikan sebesar $30 \mathrm{~kg} / \mathrm{jam}$. [4]
Dari hasil observasi, diperoleh titik temu antara masalah pengangguran, potensi kebutuhan pakan ternak ikan dan petani ikan jaring terapung, yaitu perlunya pelatihan sekaligus bantuan mesin serta pembentukan unit usaha. Salah satu solusi adalah merancang suatu mesin yang tepat guna dan sederhana untuk dapat digunakan oleh masyarakat.

Perancangan mesin pakan ikan pelet berdasarkan beberapa kriteria:

a. Mesin/alat harus sederhana (tepat guna)

b. Mesin / alat harus mobilitas

c. Mampu dioperasikan oleh masyarakat.

Secara umum pembuatan pakan ikan terdiri dari tiga bagian pokok, yaitu; proses penghancuran (pelembutan), proses pengadukan (mixing) dan proses pembuatan pelet. Dalam hal ini mesin yang dirancang merupakan gabungan dari mesin penghancur dan pelet.

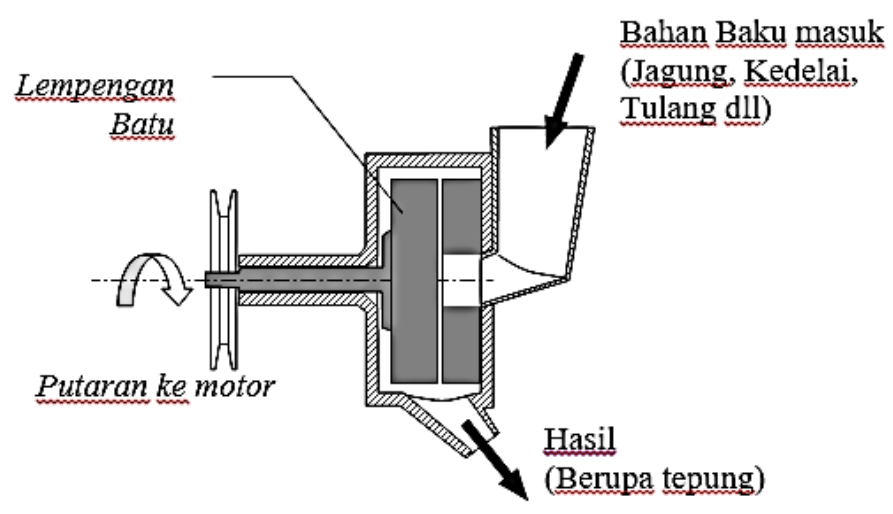

\section{Gambar 1 : Prinsip Kerja Mesin Pengolah Pakan Ikan}

Dari gambar 1 diatas dapat dijelaskan prinsip kerja mesin adalah sebagai berikut; bahan baku seperti tulang, jagung, kedelai, ubi dan lainlain, masuk mesin melalui corong, kemudian dihancurkan dengan menggunakan gesekan antara dua permukaan batu (satu bergerak yang satunya diam) yang digerakkan oleh putaran motor, yang selanjutnya menghasilkan berupa tepung.

Mesin ini dirancang untuk dapat digunakan dengan bahan baku kering (tanpa air) dan bahan baku basah (menggunakan air). 


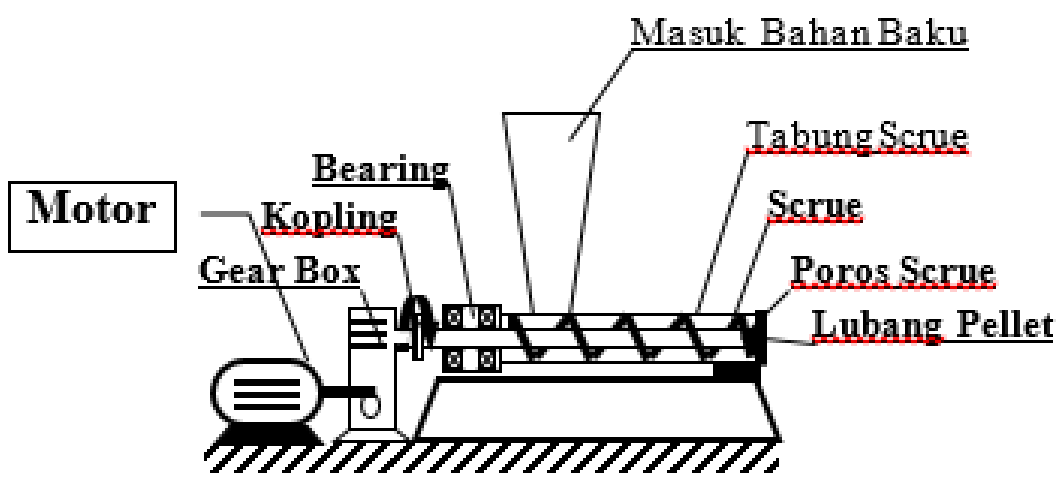

Gambar 2 : Rancangan Mesin Pengolah Pakan Ikan [5]

Prinsip dasar dari mesin Pencetak (pelet) hampir mirip dengan mesin cincang untuk daging, yaitu menggunakan screw pendorong, dan dirancang sehingga pelet yang dihasilkan lebih baik.

\section{Proses Pembuatan}

Dalam proses pembuatan, mesin penghancur dan mesin Pelet digabungkan dalam satu set unit mesin, sehingga pemakaian motor penggerak cukup satu unit untuk menggerakkan kedua mesin tersebut.

Kebutuhan meterial yang digunakan, diantaranya:

1) Mesin bensin $5 \mathrm{PK}$

2) Mesin penghancur, yang terdiri dari; poros, tabung, bearing, pully batu, pisau, plat stainless steel, dan lain-lain.

3) Mesin Pelet, yang terdiri dari poros screw, ulir screw, tabung screw, pisau pemotong dan lain-lain.

4) Gear Box

5) Rantai (sebagai kopling) dan kare pully

6) Plat baja dan rangka baja
Proses pembuatan mesin dilakukan di Dosen dan Mahasiswa melalui proses:

1) proses pembubutan, mesin bubut

2) proses pemotongan, gergaji listrik, mesin potong plat

3) proses pengelasan, las listrik, las acetilene

4) proses pembentukan, mesin lipat

5) proses pelubangan, mesin bor

6) alat bantu, palu, kikir, kompresor, ampelas, gergaji, Tap, obeng, kuncikunci, dll.

\section{Tahapan Pelatihan}

Pelatihan dilaksanakan setelah Mesin Pengolah Pakan Ikan selesai dibuat dan telah diuji coba. Hal ini untuk memastikan pada saat praktek langsung ke peserta pelatihan mesin siap untuk digunakan.

Pelatihan dilaksanakan pada tanggal 18-20 Januari 2007, dengan jumlah peserta pelatihan sebanyak 20 peserta yang berasal dari petani ikan desa Cipeundeuy.

Adapun materi yang diberikan terdiri dari:

a) Pengembangan diri, dan Kewirausahaan 
b) Dasar manajemen

c) Pengetahuan pakan ternak ikan

d) Teori dan Praktek Mesin Pengolah Pakan Ikan

Metode yang digunakan adalah pelatihan bagi orang dewasa, Andragogi. Peserta selain diberi materi pelatihan juga diajak untuk berperan aktif dalam menyelesaikan suatu kasus yang terjadi di lapangan.

Pelatihan ini melibatkan lima instruktur yang berasal dari berbagai ahli dibidangnya. Instruktur tersebut adalah; (1) Ahmad Munandar, ST., MT. (Manajemen Produksi), (2) Dadang Supriatna, Drs., MT (Analis Kimia), (3) Agus Sunarya, Ir. (Teknik Produksi), (4) Udin Komarudin, Ir., MT. (Teknik Konstruksi Mesin) dan Nurwathi, Ir., MT. (Administrasi Usaha).

Pasca pelatihan, dilakukan evaluasi pelatihan untuk mengetahui hasil pelatihan baik pengetahuan maupun keterampilan peserta. Evaluasi juga dilakukan untuk penyelenggaraan proses pelatihan, dimana peserta melakukan penilaian terhadap penyelenggara.

\section{HASIL DAN PEMBAHASAN}

Dari permasalahan yang ditemukan, diperlukan suatu hubungan yang saling menguntungkan antara masalah, potensi dan peluang. Memerlukan kerjasama antara pemerintahan setempat, warga sekitar, lembaga penelitian, bahkan industry pakan ternak dengan pemilik petani ikan (jaring terapung). Kerjasama tersebut dapat terwujud melalui:

a. Kebijakan Pemerintah setempat yaitu dengan memaksimalkan potensi daerah terutama penyediaan pakan ikan yang diolah sendiri.

b. Kerja sama antara warga setempat dengan pengusaha jaring terapung, berupa: a) Pembuatan pakan ternak ikan, pelet oleh warga sekitar, b) petani ikan membeli pakan ternak ikan dari warga sekitar.

c. Kerja sama lembaga penelitian dengan warga sekitar berupa penciptaan alternatif produksi melalui pelatihan khususnya cara pembuatan pakan ternak ikan, yang memenuhi standar kebutuhan petani ikan.
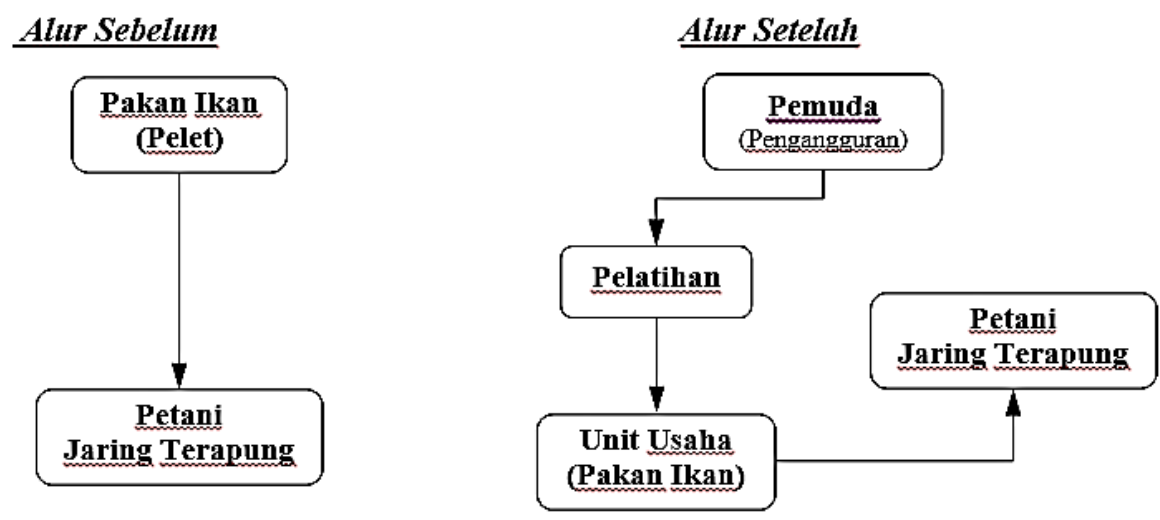

Gambar 3 : Perbedaan sebelum dan rencana solusi permasalahan 
Berdasarkan observasi dan evaluasi pembuatan mesin pengolah pakan ikan, maka kemampuan tim, maka diputuskan untuk dihasilkan mesin pengolah pakan ikan seperti membuat mesin pengolah pakan ikan beserta gambar dibawah ini: dengan pelatihannya. Setelah dilakukan proses

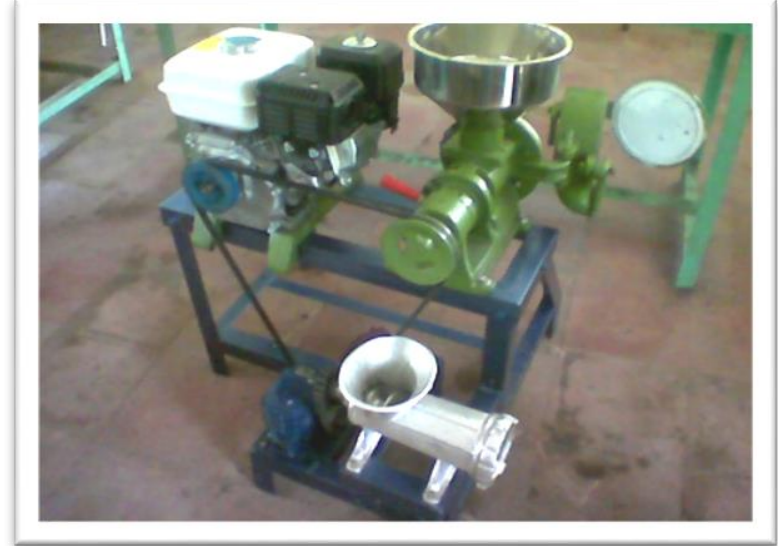

Gambar 4 : Mesin Pengolah Pakan Ikan

Setelah pembuatan mesin pengolah ikan Cipeundeuy, dengan jumlah peserta sebanyak selesai, selanjutnya dilakukan pelatihan bagi 20 orang. para petani tambak ikan dan para pemuda desa

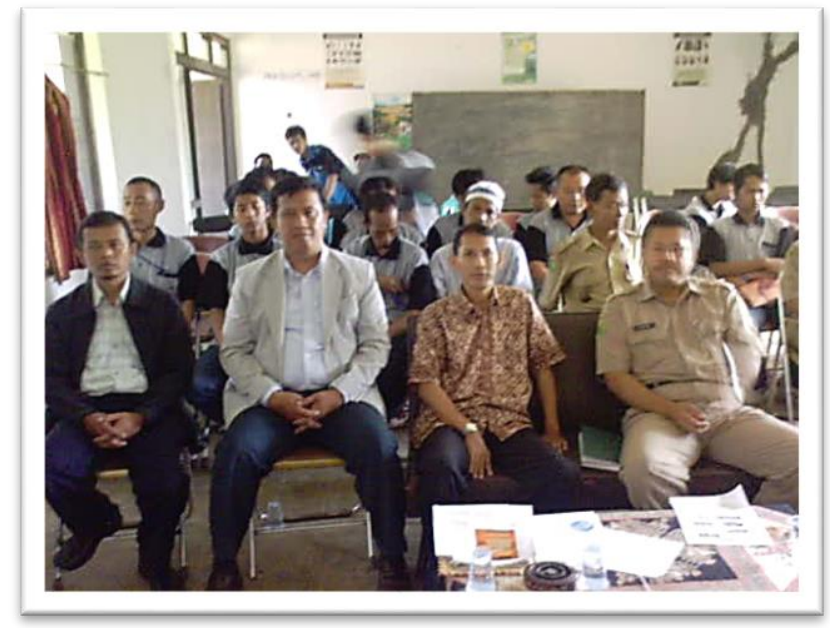

\section{Gambar 5 : Pembukaan Pelatihan}

Dengan materi yang meliputi, manajemen produksi, pengenalan bahan baku pelet, pengoperasian mesin pengolah pakan ikan, dan administrasi usaha, dihasilkan pemahaman dan keterampilan yang sangat baik dari para peserta pelatihan.
Dari hasil evaluasi diperoleh, bahwa setelah pelatihan peserta bertambah kemampuanya, dengan nilai rata-rata 80.1 , dengan rincian sebagai berikut: 
P-ISSN: 2745-5912

E-ISSN: 2745-9047

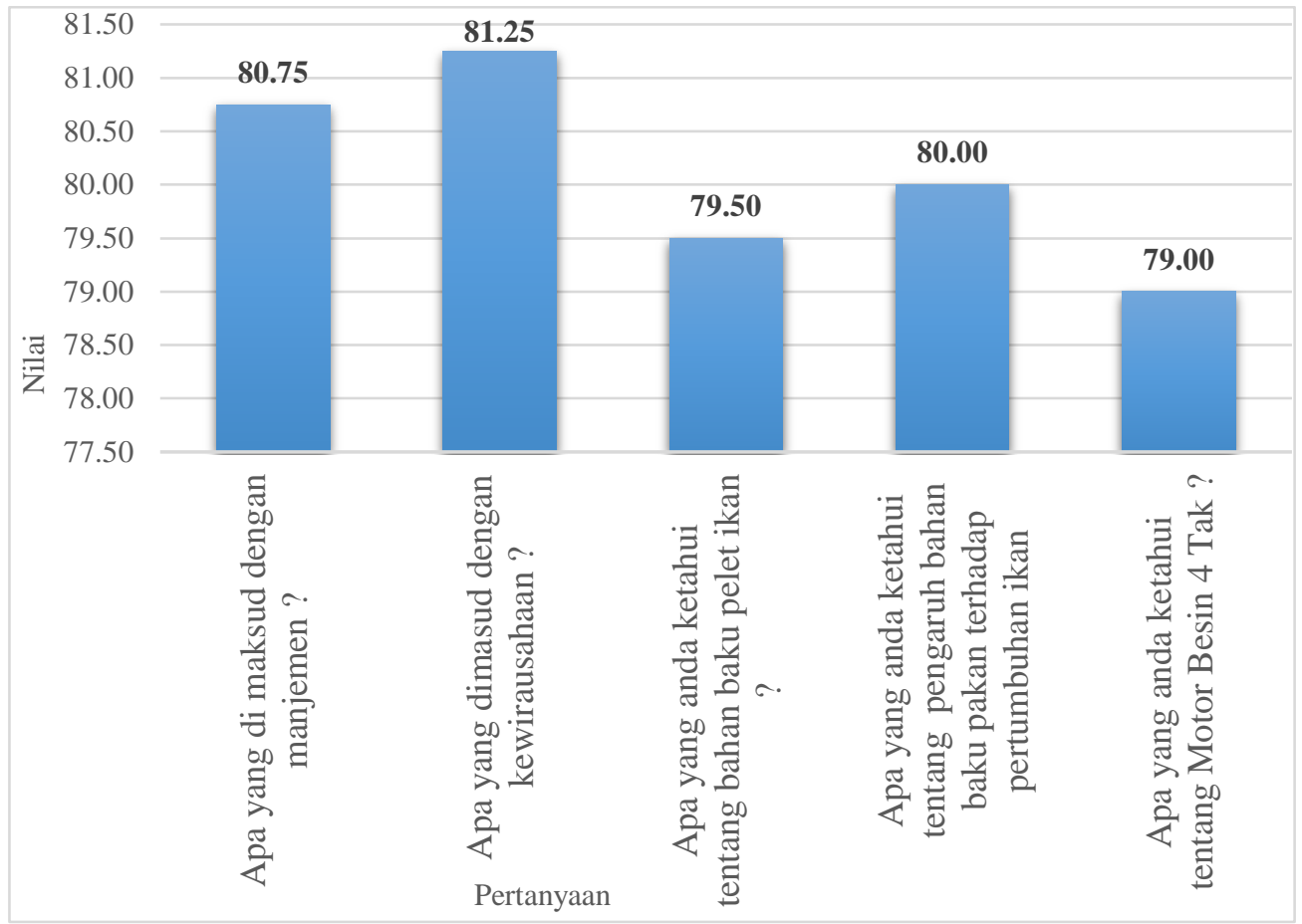

Gambar 6 : Pemahaman Peserta Hasil Pelatihan

Sementara dari hasil pelatihan pengoperasian ikan yang sesuai dengan harapan petani, hal ini mesin pengolah pakan ikan, dihasilkan pakan dapat dilihat dari gambar dibawah ini:

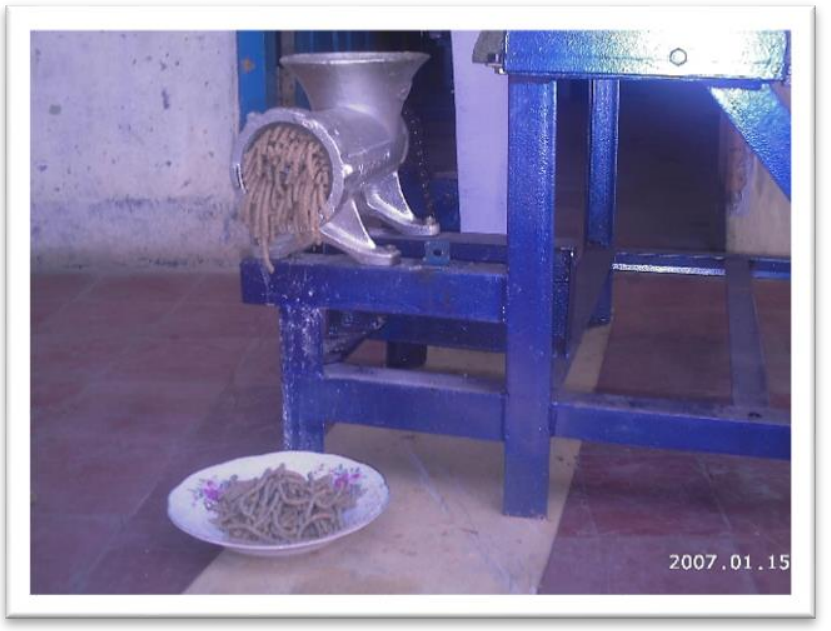

Gambar 7 : Contoh hasil Pelet ikan dari Mesin Pengolah Ikan

Pasca pelatihan, selanjutanya dilakukan

kegiatan pendampingan berupa penyuluhan ke

kelompok usaha yang didirikan dengan mengujungi langsung ke tempat kelompok. Pendampingan dilakukan 3 kali selama satu bulan, dengan kegiatan sebagai berikut:
Kunjungan-1 Penyuluhan perawatan dan penggunaan mesin Pakan Ternak Ikan

Kunjungan-2 Penyuluhan Manajemen Keuangan

Kunjungan-3 Penyuluhan manajemen dan kualitas 
Diharapkan dengan pendampingan, masalahmasalah yang dihadapi kelompok dapat terpecahkan dan dalam jangka panjang akan menjadi kelompok binaan / mitra serta menjadi koperasi pakan ikan di desa Cipeundeuy.

\section{KESIMPULAN DAN SARAN}

\section{Kesimpulan}

Dari penanganan pasca pengabdian masyarakat kepada kelompok masyarakat, kegiatan ini sangat bermanfaat dan membantu masyarakat setempat, terutama mengangani pengangguran, kebutuhan pakan ikan, pellet ikan, dan peningkatan pendapatan masyarakat terutama pemuda. Pelatihan pengolahan pakan ikan menggunakan mesin pengolah pakan ikan dapat membantu petani ikan menyediakan pakan ikan mandiri, sehingga membantu petani ikan mengurangi beban biaya produksi.

\section{Saran}

Pemerintah Daerah khususnya Pemda Kabupaten Bandung agar menggulirkan program-program peningkatan kecakapan hidup masyarakat guna mengatasi permasalahan lingkungan serta meningkatkan kesejahteraan masyarakat terutama yang menjadi sumber pendapatan asili daerah Kabupaten Bandung, salah satunya budidaya ikan di desa Cipeundeuy, kecamatan Cipeundeuy, kabupaten Bandung.

\section{DAFTAR PUSTAKA}

[1] E. Z. Nasution, "Studi Pembuatan Pakan Ikan Dari Campuran Ampas," Jurnal Sains Kimia, vol. 10, pp. 40-45, 2006.

[2] N.B.P.Utomo, "Effect of Different Feeding on Feed Conversion and Growth of Common Carp," Jurnal Akuakultur Indonesia, vol. 4, p. 63-67, 2005.

[3] B. Hepher, Commercial Fish Farming, New York, 1981, p. 261.

[4] S. Uslianti, "Rancang Bangun Mesin Pelet Ikan Untuk Kelompok Usaha Tambak Ikan," Jurnal ELKHA, vol. 6, pp. 21-24, 2014.

[5] T. Sato, Menggambar Mesin menurut standar ISO, Jakarta: Pradnya Paramita, 1986. 